\title{
Role of capillary adhesion in the friction peak during the tacky transition
}

\author{
Tianyan GAO, Jiaxin YE, Kaisen ZHANG, Xiaojun LIU, Yan ZHANG, Kun LIU* \\ Institute of Tribology, School of Mechanical Engineering, Hefei University of Technology, Hefei 230009, China \\ Received: 16 January 2020 / Revised: 21 April 2021 / Accepted: 04 May 2021 \\ (C) The author(s) 2021.
}

\begin{abstract}
The friction peak that occurs in tire-road sliding when the contact changes from wet to dry was previously attributed to capillary cohesion, van der Waals attraction, and surface roughness, but the detailed mechanisms have yet to be revealed. In this study, friction and static contact experiments were conducted using a custom-built in situ optical microtribometer, which allowed us to investigate the evolution of the friction, normal load, and contact area between a polydimethylsiloxane (PDMS) film and a silicon nitride ball during water volatilization. The friction coefficient increased by $100 \%$, and the normal force dropped by $30 \%$ relative to those in the dry condition during the wet-to-dry transition. In static contact experiments, the probe indentation depth increased, and the normal load decreased by $\sim 60 \%$ as the water evaporated. Combining the friction and static contact results, we propose that the large friction peak that appeared in this study can be attributed to the combined effects of increased adhesive capillary force and increased plowing during the wet-to-dry transition.
\end{abstract}

Keywords: friction peak; capillary adhesion; tacky condition; polydimethylsiloxane (PDMS) film; silicon nitride

\section{Introduction}

Humidity profoundly affects many tribological systems. One everyday example is automotive windshield wipers, which slide smoothly if the glass surface is either wet or dry, but often develop squeaking and stick-slip behavior in partially wet conditions [1]. Traditionally, the presence of a liquid lubricates the surface to reduce friction, but many studies have found that the friction coefficient is higher in wet conditions than that in dry conditions when the film thickness reaches the nanoscale. During the wet-to-dry transition, a short period of increased friction has been repeatedly observed and is often referred to as the tacky transition in the literature [2,3]. During the wet-to-dry transition, Deleau et al. [2] observed that rubber friction was approximately $37 \%$ higher than that under dry conditions. When a $300 \mathrm{~nm}$ oil film was added to the metal surface, the rubber-steel friction coefficient increased by $3 \times$ [3]. Roberts and Tabor [4] studied the peak frictional force as a function of film thickness between a rubber sphere and a glass plate and found that the friction increased rapidly for films less than $6 \mathrm{~nm}$ thick. Therefore, the liquid film in the contact area plays an important role in increasing the friction coefficient.

In 2008, Le Rouzic et al. [5] suggested that in the tacky regime, the attraction from water capillary bridges between rubber and a glass substrate pulls the surfaces into closer contact; consequently, the real contact area in the tacky regime is larger than that for perfectly dry contact. Bocquet et al. [6] pointed out that liquid bridges induce significant cohesion, which can increase friction. Flies inject liquid into the space between the plate and the substrate, which generates capillary bridges, enabling them to walk on a vertical glass window. Drechsler and Federle [7] noted that a thinner fluid film between a pretarsal pad and a glass

* Corresponding author: Kun LIU, E-mail: liukun@hfut.edu.cn 
surface results in a more strongly curved meniscus and a more negative Laplace pressure. In many cases, the contribution of capillary bridges to the wall-wall attraction may be significantly larger than the contribution from the direct wall-wall interaction [3].

Johnson et al. [8], Kendall [9], Tabor [10], Derjaguin et al. [11], and Maugis [12] pioneered the modeling and evaluation of adhesion between elastic solids. Recently, Reedy [13], Hill et al. [14], and Dickrell et al. [15] developed models and tools for elastic contact adhesion involving thin elastic layers. In aqueous environments, Loskofsky et al. [16] explored the underwater work of adhesion between elastic silicone lenses using the JKR (Johnson-Kendall-Roberts) technique technique. However, few studies have analyzed the evolution of the contact as the conditions change from wet to dry and the accompanying friction peak.

In this study, the friction behavior of rubber was analyzed to gain more insight into the friction force peak phenomenon in blade/windshield and tire/road contact. A ball-on-flat configuration was used to observe the friction force peak, and the water film thickness around the contact, contact radius, normal force, and friction force with and without sliding were monitored during the wet-to-dry transition. The combined results of the friction and static contact tests were used to further elucidate the effect of water on rubber sliding during the wet-to-dry transition.

\section{Material and methods}

\subsection{Specimens and preparation}

A silicon nitride ball and polydimethylsiloxane (PDMS) film were selected as the contact pair in this study to facilitate observation of the contact interface. A $2.89 \mathrm{~mm}$ diameter silicon nitride ball with a contact angle of $83^{\circ}$ against water and an average roughness $\left(R_{\mathrm{a}}\right)$ of $89 \mathrm{~nm}$ (as illustrated in Fig. 1) was used as the probe. Sheets (thickness: approximately $400 \mu \mathrm{m}$ ) of PDMS were prepared using a Sylgard 184 Silicone Elastomer kit purchased from Dow Corning. The curing agent and base were first mixed at a prescribed ratio of $1: 5$ and degassed for $20 \mathrm{~min}$. The mixture was transferred to clean glass slides (pre-sonicated using propanol and deionized water) mounted inside a spin-coater,

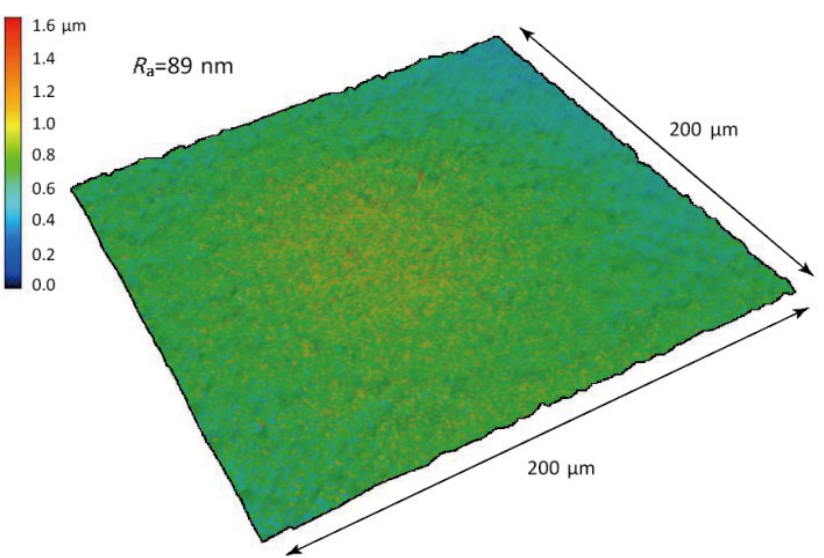

Fig. 1 Surface topography of silicon nitride ball was measured based on unwrapped height maps of a $200 \mu \mathrm{m} \times 200 \mu \mathrm{m}$ area. The average roughness of $\mathrm{Si}_{3} \mathrm{~N}_{4}$ sphere was $89 \mathrm{~nm}$.

which was rotated at $500 \mathrm{rpm}$ for $20 \mathrm{~s}$. The glass slides were then baked at $120^{\circ} \mathrm{C}$ for $30 \mathrm{~min}$ and cooled to room temperature $\left(25^{\circ} \mathrm{C}\right)$ [17]. The water wetting angle of the PDMS was $113^{\circ}$, and the modulus was $4.76 \mathrm{MPa}$, which was measured through an indentation test based on the JKR theory (diameter of $\mathrm{Si}_{3} \mathrm{~N}_{4}$ ball: $6 \mathrm{~mm}$; average roughness: $73 \mathrm{~nm}$; thickness of PDMS plate: $5 \mathrm{~mm}$; speed: $1 \mu \mathrm{m} / \mathrm{s}$; peak force: $85 \mathrm{mN}$; maximum contact radius: $0.29 \mathrm{~mm}$ ) $[8,18-20]$.

\subsection{Friction testing}

Tribology experiments were performed using an in situ optical microtribometer, as shown in Fig. 2(a). The tribometer was nominally identical to that used by Krick et al. [21]. $A \mathrm{Si}_{3} \mathrm{~N}_{4}$ sphere was attached to a soft cantilever flexure end with a vertical stiffness of $835 \mathrm{~N} / \mathrm{m}$ and a lateral stiffness of $2355 \mathrm{~N} / \mathrm{m}$. The lateral and vertical displacements of the flexure were measured using two capacitive sensors $( \pm 1 \mathrm{~nm})$. The flexure was driven vertically by a piezo stage with a $250 \mu \mathrm{m}$ travel distance. Friction experiments were performed on a PDMS film/glass slide connected to a linear table. A $20 \times$ microscope objective was used to monitor the contact from underneath the glass slide. The tribometer was able to measure the friction and normal force up to $1 \mathrm{~N}$ with an uncertainty of $\pm 14 \mu \mathrm{N}$.

Friction experiments were conducted in a standard laboratory environment and included wet, tacky, and dry conditions as the interfacial water evaporated. They were performed using a $\mathrm{Si}_{3} \mathrm{~N}_{4}$ ball/PDMS film with a reciprocating length (one direction) of $200 \mu \mathrm{m}$, 

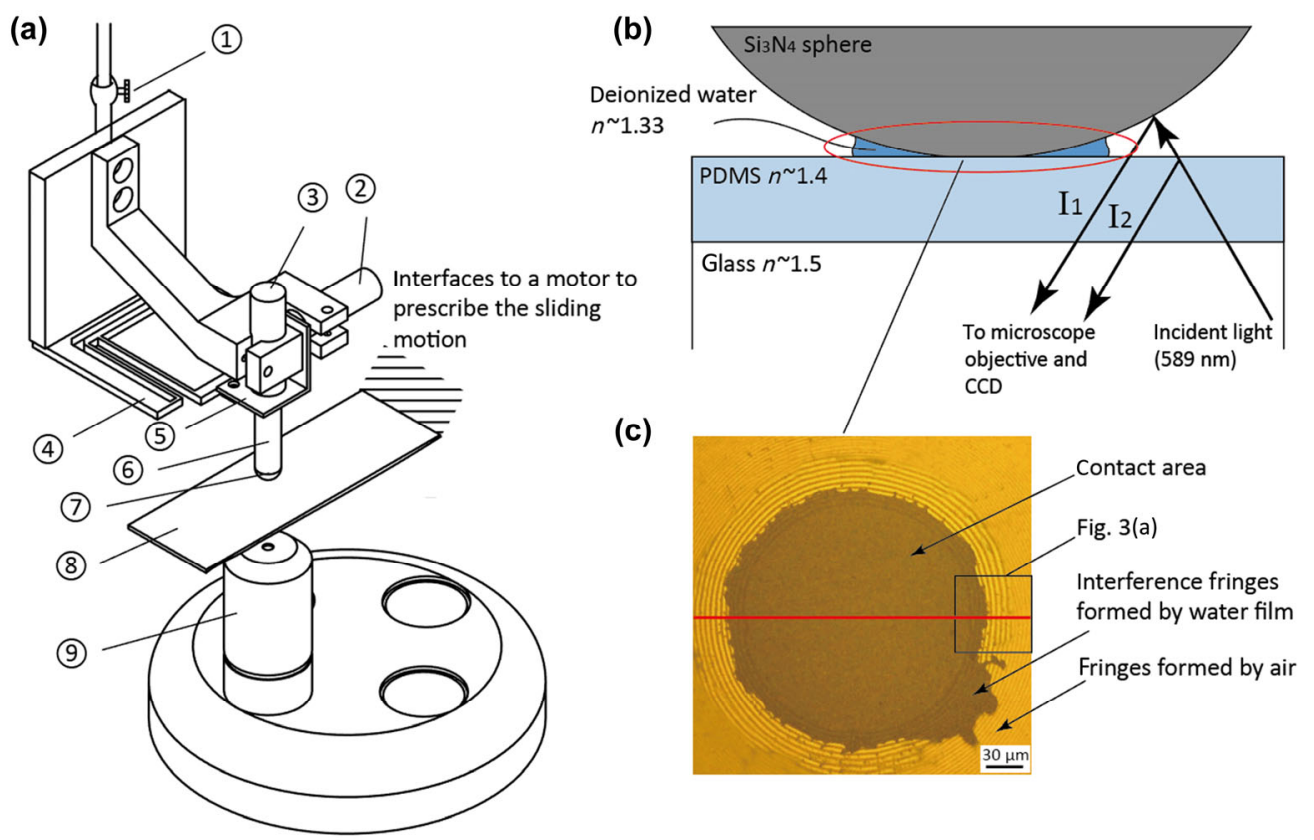

Fig. 2 (a) In situ optical microtribometer used in this study. The schematic shows only the primary structure. A glass slide was fixed on the base driven by a linear table. Capacitive displacement sensors improved the measuring accuracy of load and tangent forces. Main components include (1) rock and tilt head; (2)(3) capacitive displacement sensors; (4) cantilever beam; (5) metal corner piece; (6) nylon bolt; (7) $\mathrm{Si}_{3} \mathrm{~N}_{4}$ ball; (8) slides cured with PDMS film; (9) microscope objective. Custom software written in Labview ${ }^{\mathrm{TM}}$ was used to collect and analyze data. (b) Schematic of the optical pathway. A monochromatic light source with a central wavelength of $589 \mathrm{~nm}$ was used. Light passes through the microscope objective and the transparent counter sample. One beam of light was reflected on the upper surface of PDMS, and another beam of light was transmitted through the liquid and reflected on the surface of the $\mathrm{Si}_{3} \mathrm{~N}_{4}$. (c) $\mathrm{An}_{\mathrm{optical}}$ contact image with a thin water film in the contact area.

sliding speed of $20 \mu \mathrm{m} / \mathrm{s}$, and normal load of $3 \mathrm{mN}$. The experiment was first run for a few cycles under dry conditions. Then, deionized water (approximately $0.1 \mathrm{~mL}$ ) was injected onto the PDMS film to wet the contact interface. Finally, the test was run for a long time (approximately $1 \mathrm{~h}$ ) until the contact area changed from wet to dry.

\subsection{Static contact testing}

To study the influence of water volatilization on adhesion, the variation in the normal load during the water volatilization process under static contact was studied. Static contact tests were conducted using a microtribometer under dry and wet conditions. For the dry condition, the $\mathrm{Si}_{3} \mathrm{~N}_{4}$ ball was brought into contact with the PDMS film using the piezoelectric stage; a maximum normal load of $1 \mathrm{mN}$ was applied. For the wet condition, $0.3 \mu \mathrm{L}$ deionized water was injected onto the PDMS film prior to contact. Then, as the water evaporated, the normal force was recorded, and images were acquired at half-second intervals.

\subsection{Contact profile characterization}

The contact profile characterization method was based on the efforts of Krick et al. [21] and Rowe et al. [22]. The microscope objective was equipped with a monochromatic light source (central wavelength: $589.3 \pm 10 \mathrm{~nm}$ ). A schematic of the optical pathway is shown in Fig. 2(b). The water and air film thicknesses near the contact edge were calculated based on the interference fringe patterns, as illustrated in Fig. 3. The condition for generating destructive dark interference fringes is

$$
\delta=(2 m+1) \pi=\frac{2 \pi}{\lambda}\left(2 n d+\frac{\lambda}{2}\right)
$$

where $\delta$ is the optical path difference, $m$ is the order of the destructive interference fringe, $\lambda$ is the central wavelength, $n$ is the refractive index of the intermediate medium ( $n=1$ for air, $n=1.33$ for water), and $d$ is the liquid or air film thickness [23]. First, the position of each dark fringe was calibrated relative to the center 

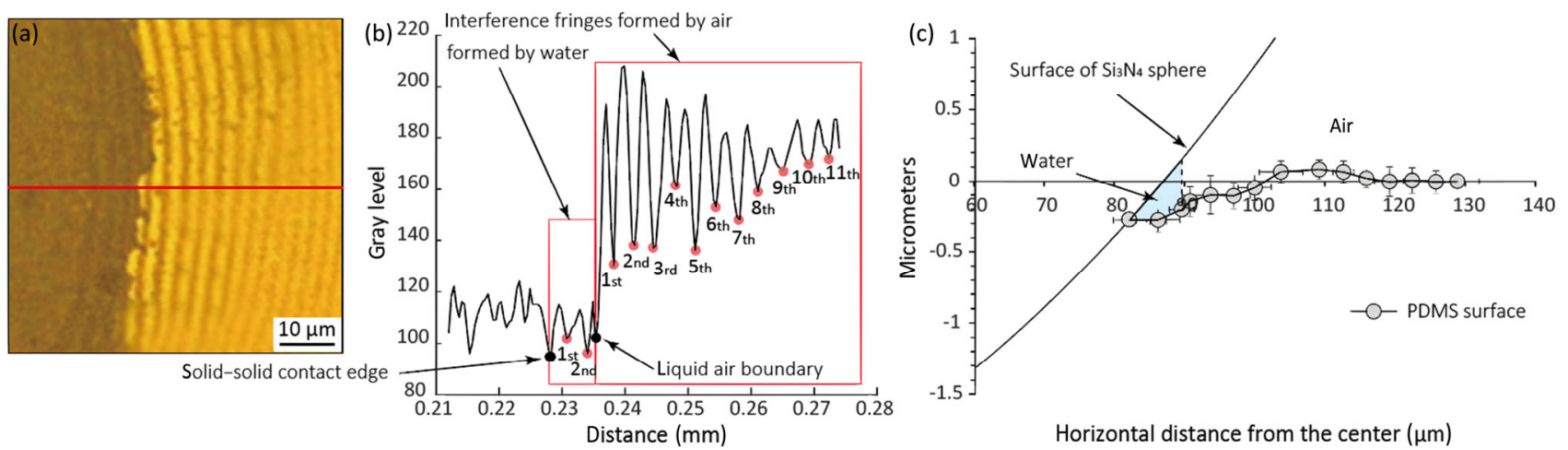

Fig. 3 (a) Interference fringes formed by water and air films near the contact edge. (b) The gray value curve of the red line in (a) was used to find the solid-solid contact edge and the destructive interference fringes formed by water and air films. (c) Outlines of the $\mathrm{Si}_{3} \mathrm{~N}_{4}$ sphere and PDMS film based on the calculated thickness of thin films near the contact edge. PDMS profile far from the contact center was set as zero height.

of the Hertzian contact by extracting the grayscale values on a straight line passing through the center of the contact. By comparing the image to the gray value curve, the interference fringes formed by the water and air films could be distinguished. Using Eq. (1), the thickness of the thin film (water or air) at the center of each dark fringe was calculated as follows:

$$
d=\frac{m}{2 n} \lambda
$$

Finally, the outline of the $\mathrm{Si}_{3} \mathrm{~N}_{4}$ sphere was used to derive the profile of the PDMS film, as shown in Fig. 3(c). The PDMS profile far from the contact edge $(>40 \mu \mathrm{m})$ was unchanged before and after contact and was set as the zero height. This approach is similar to that adopted by Dickrell et al. [15]. To obtain statistics on the PDMS surface profile, this fringe counting algorithm was repeated along three lines passing through the contact center with different angles, and the uncertainties are reported as error bars in Fig. 3(c).

\section{Results}

\subsection{Friction coefficient}

The friction test results of a $\mathrm{Si}_{3} \mathrm{~N}_{4}$ ball sliding against a PDMS film under dry and wet conditions are shown in Fig. 4. Noticeable hysteresis was observed in the friction loop, and a calculation window of \pm $0.04 \mathrm{~mm}$ was used to calculate the average friction coefficient within each cycle. The dry sliding friction coefficient was approximately 0.73 . Twenty seconds after water were added, the friction loop showed less hysteresis, but the average friction coefficient did not change ( 0.72).

The evolution of the friction coefficient, normal load, and contact morphology from dry to wet and back to dry conditions is shown in Fig. 5. Sets of twenty raw measurements were averaged to reduce the number of plotted data points. The uncertainty in the average friction coefficient is based on the twenty data points that were averaged. The friction coefficient decreased to a minimum of 0.53 immediately after the water drop was injected. Further sliding increased the friction coefficient to a value comparable to that under the dry condition $(\sim 0.73$, image 1, Fig. $5(\mathrm{c}))$. As the interfacial

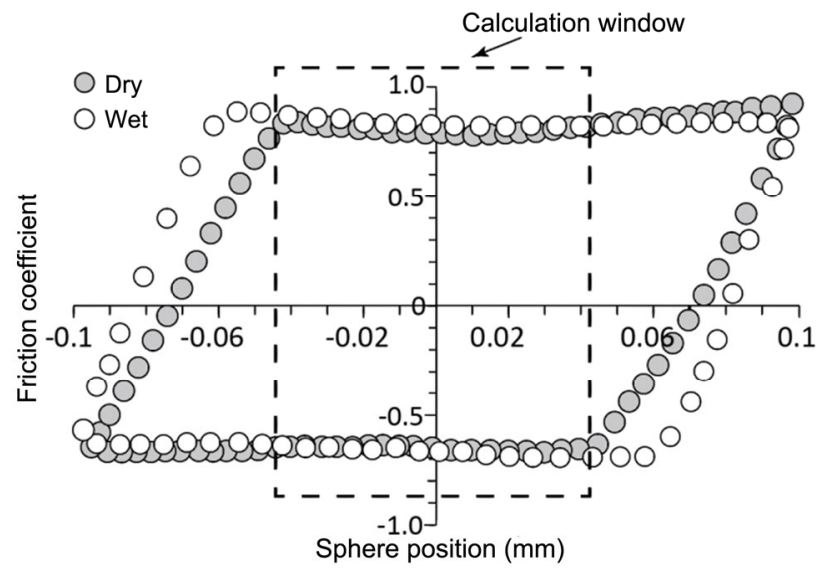

Fig. 4 Friction coefficient versus prope position in dry and wet conditions (normal load: $3 \mathrm{mN}$; velocity: $20 \mu \mathrm{m} / \mathrm{s}$; reciprocating length: $200 \mu \mathrm{m})$. 


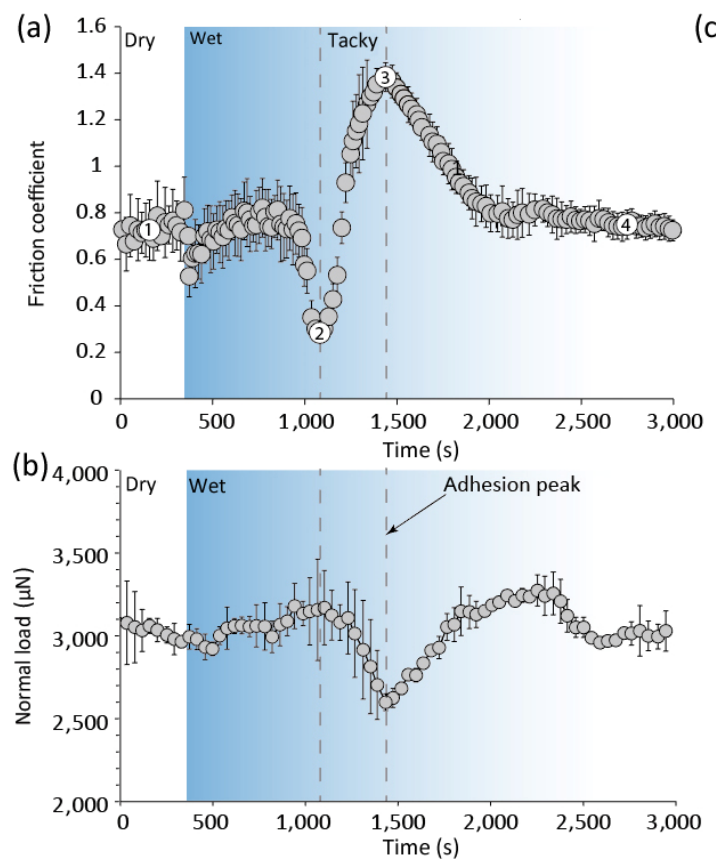

(c)
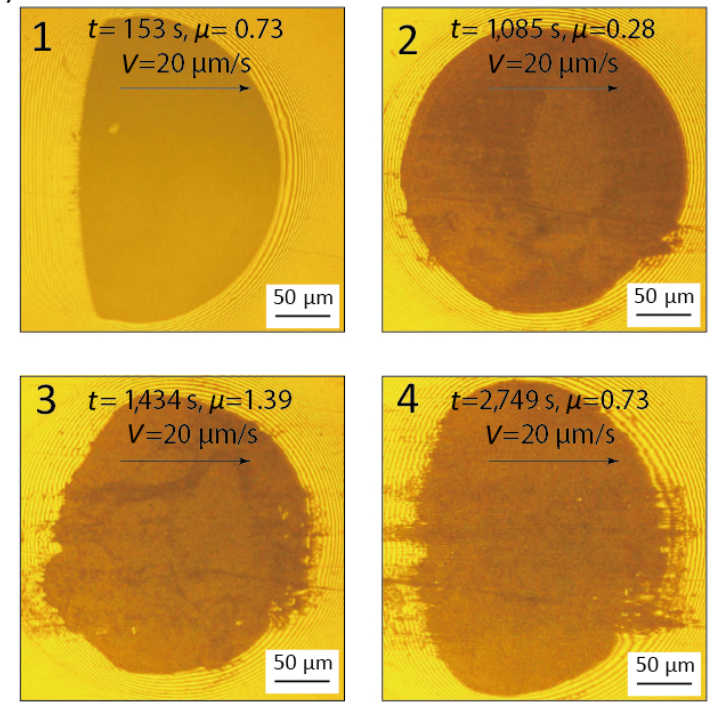

Fig. 5 The friction test result of a $\mathrm{Si}_{3} \mathrm{~N}_{4}$ ball sliding against a PDMS film (normal load: $3 \mathrm{mN}$; velocity: $20 \mu \mathrm{m} / \mathrm{s}$; reciprocating length: $200 \mu \mathrm{m}$ ). (a) Friction coefficient evolution versus time with contact area changing from wet to dry. The four images were all chosen from the calculation window. (b) Normal load evolution versus time during the transition from wet to dry in the friction testing. (c) Images of the contact zone at time of $t=153 \mathrm{~s} ; t=1,085 \mathrm{~s} ; t=1,434 \mathrm{~s} ; t=2,749 \mathrm{~s}$.

water volume decreased with increasing number of sliding cycles, the friction coefficient further decreased to a minimum of 0.28 (image 2 , Fig. 5(c)), increased to a maximum of 1.39 (image 3, Fig. 5(c)), and decreased again to $\sim 0.73$ (image 4 , Fig. $5(\mathrm{c})$ ). The normal load had an inverse trend to that of the friction coefficient, and a marked reduction in normal load $(\sim 0.5 \mathrm{mN})$ was observed with the frictional peak during the tacky transition. This result supports previous reports on the frictional peak observed during the wet-to-dry transition in rubber-glass/metal tribopairs [2, 3]. The results shown in Fig. 5 were reproducible in our preliminary experiments.

\subsection{Normal load variation during water volatilization}

The evolution of the normal force as the pre-existing interfacial water evaporated during the static contact experiment is plotted in Fig. 6(a) (duration of $4 \mathrm{~h}$ ). An initial normal load of $1 \mathrm{mN}$ was applied. As the water evaporated, the normal force slowly decreased
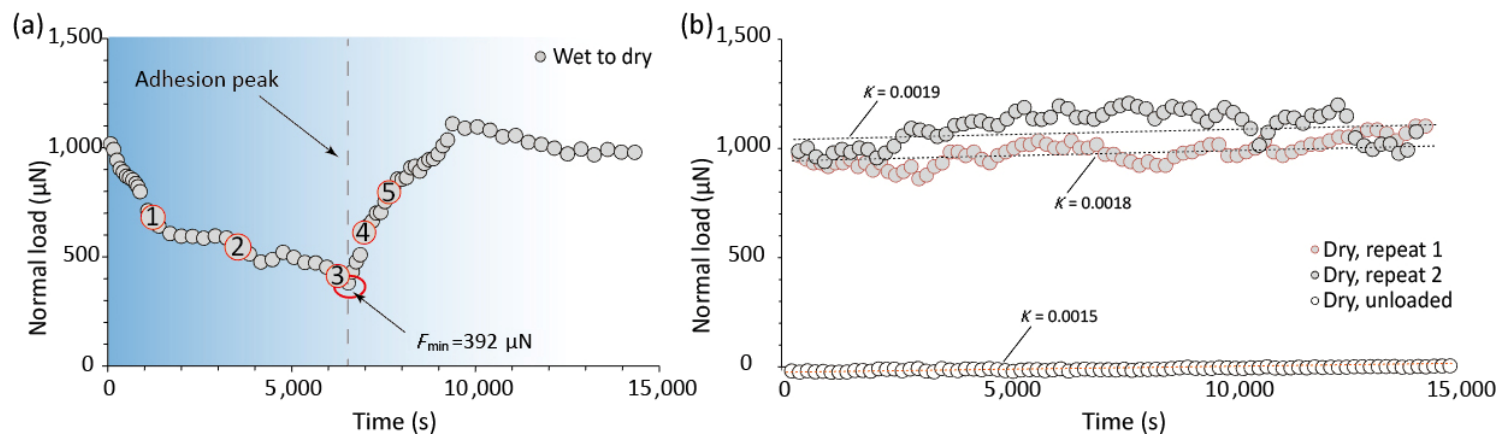

Fig. 6 The evolution of normal force versus time in static experiments. (a) Static contact normal force versus time as pre-existing interfacial water evaporated in standard lab environment for a duration of $4 \mathrm{~h}$. Contact profiles at five selected intervals were marked with numbered data labels and analyzed using the methods described in Fig. 3. (b) Normal force signal versus time for control experiments in which the cantilever flexure was unloaded (white) and loaded (gray) without interfacial water for a duration of $4 \mathrm{~h}$. The normal force signal had an uptrend drift of $\sim 3 \mu \mathrm{N} / \mathrm{h}$ for all cases. 
to a minimum of $390 \mu \mathrm{N}$ and recovered to $1 \mathrm{mN}$ after $\sim 3.6 \mathrm{~h}$. Control experiments in which the cantilever flexure was unloaded and loaded $(1 \mathrm{mN})$ without interfacial water were run for a duration of $4 \mathrm{~h}$ in the same standard lab environment, and the results are shown in Fig. 6(b). The control experiment results had a maximum normal force variation of $13 \mu \mathrm{N}$ over $4 \mathrm{~h}$ (transducer drift of $\sim 3 \mu \mathrm{N} / \mathrm{h}$ ). This suggests a strong interfacial adhesive force independent of the creep of the PDMS during the wet-to-dry transition, as shown in Fig. 6(a). The height profiles of the $\mathrm{Si}_{3} \mathrm{~N}_{4}$ sphere and PDMS film at selected intervals were analyzed using the described methods and are shown in Fig. 7. During the first $2 \mathrm{~h}$ of the wet-to-dry transition, the solid-solid contact radius and normal force decreased, and the probe indentation depth increased (Fig. 7(a)); thereafter, the contact radius and normal load increased, and the indentation depth decreased. A noticeable tensile zone similar to that reported by Hill et al. [14] and Dickrell et al. [15] was discernable near the contact edge after $\sim 2 \mathrm{~h}$.

\section{Discussion}

As shown in Fig. 5(a), the friction coefficient increased to its maximum value, which is denoted as the friction peak, during the wet-to-dry transition. The maximum friction coefficient in the tacky condition increased by up to $100 \%$, and the normal force decreased by $\sim 30 \%$ compared to those in the dry condition. In 2008, Deleau et al. [2] showed that rubber sliding against a glass plate had a friction force peak that was only $35 \%$ higher than that under dry conditions. They

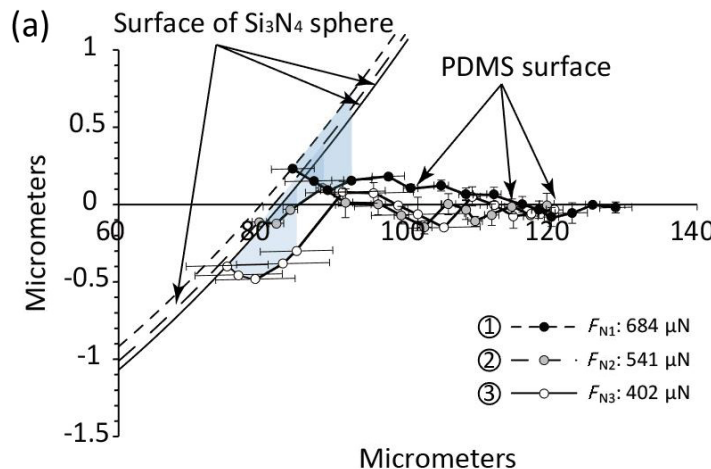

attributed this tacky regime to small entrapped water droplets, which might induce capillary adhesion. In the static contact experiment in this study, the normal load decreased to a minimum of $392 \mu \mathrm{N}$ and then increased during water volatilization. Factors causing the load reduction might include water film thinning, PDMS creep, and adhesion caused by interfacial water. The control experiments (Fig. 6) and published studies [4] generally exclude PDMS creep and water film thinning as major factors affecting the normal force. Interfacial adhesive forces caused by nano/micro/macroscale liquid bridges within and near the contact were likely responsible for the large normal force variation in the static contact experiment.

The attractive capillary force between contacting asperities is affected by the relationship between the height of the asperities and the thickness of the liquid film [24]. In 2009, Megias-Alguacil and Gauckler [25] stated that attractive capillary forces can be found in the hydrophobic domain at short interparticle distances. Within a range of 20 to $200 \mathrm{~nm}$, the hydrophobic microspheres in water exhibit a strong attraction [26]. Even the coefficient of static friction depends on the capillary condensation of water vapor between the asperities, leading to the formation of water bridges [5]. Combining the friction and static contact test results, we believe that the friction peak in the tacky regime is a result of the increased probe indentation depth and decreased normal load. At the beginning of the friction experiment, capillary adhesion did not occur because the contact was fully flooded (condition 1, Fig. 8(b)). As the water evaporated, the adhesive capillary force and probe indentation depth

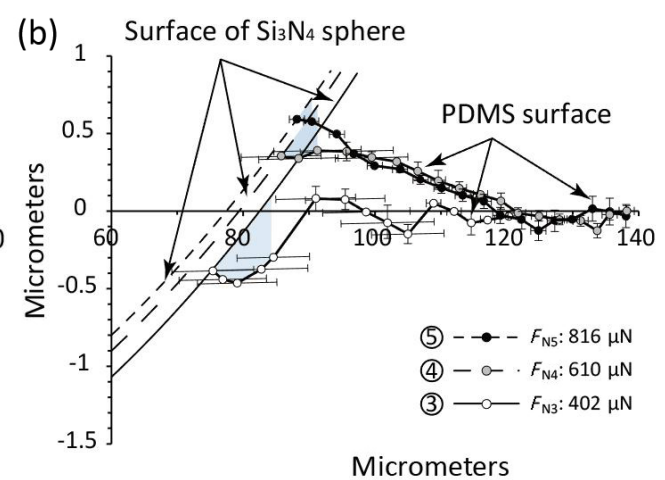

Fig. 7 Height profiles of the $\mathrm{Si}_{3} \mathrm{~N}_{4}$ sphere and PDMS film at selected intervals marked in Fig. 6(a). (a) The solid-solid contact radius and the normal load decreased, and the indentation depth increased in the first $2 \mathrm{~h}$ of the wet-to-dry transition. (b) The solid-solid contact radius and the normal load increased, and the indentation depth decreased $2 \mathrm{~h}$ after the wet-to-dry transition started. 


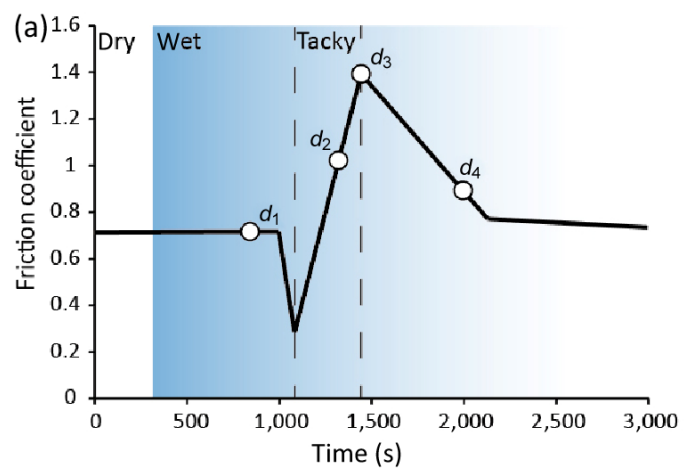

(b)

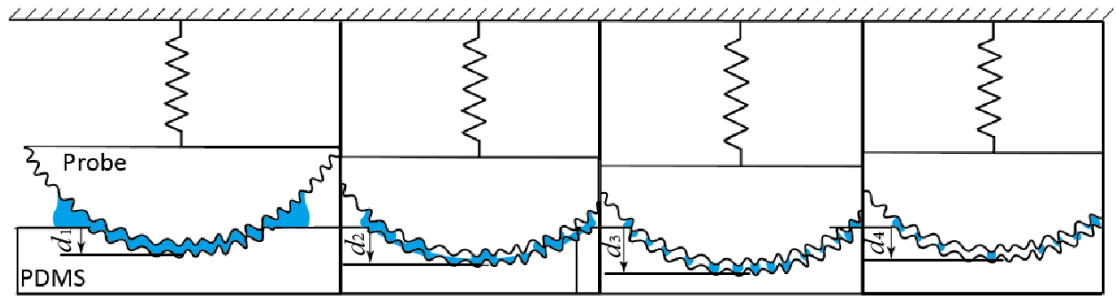

1) Without adhesion 2) Adhesion increased 3) Adhesion peak 4) Adhesion decreased

Fig. 8 (a) Schematic of friction coefficient evolution. (b) Illustration of the indentation depth of $\mathrm{Si}_{3} \mathrm{~N}_{4}$ sphere and the distribution of water droplets in contact area during water volatilization.

increased with the formation and evolution of a macro liquid bridge around the contact edge and nano/microscale liquid bridges between the contact asperities (condition 2, Fig. 8(b)). The friction coefficient peaked when the normal load was minimized and the capillary adhesion and indentation depth were maximized (condition 3, Fig. 8(b)). As the water evaporated further, the adhesive capillary force diminished, and the contact gradually returned to its initial state (condition 4, Fig. 8(b)). During the tacky regime, the maximum increase in the friction coefficient relative to that of dry sliding was $100 \%$ in this study compared with the $35 \%$ observed by Deleau et al. [2] when sliding a rubber sphere against a flat glass plate. The larger increase in friction in this study may be due to the different experimental setup (rigid sphere on a soft thin film rather than a rubber sphere on a rigid plane). Other factors that might contribute to the friction peak and require more systematic investigations include increased viscous traction, stick-slip behavior, and adhesion hysteresis [3, 19, 27-29].

Another interesting observation in the results is the increasing indentation depth with decreasing contact radius observed during the wet-to-dry transition, as shown in Fig. 7. According to the JKR theory [8], the contact radius increases with the depth of indentation. We attribute this phenomenon to the presence of a water film at the interface, which significantly reduced the surface energy of the contact.

\section{Conclusions}

This study investigated the mechanisms of the friction peak that often appears in blade-windshield and tire-road contact during the wet-to-dry transition. The friction coefficient of a $\mathrm{Si}_{3} \mathrm{~N}_{4}$ ball against a PDMS film increased by up to $100 \%$, and the normal force decreased by $\sim 30 \%$ during the wet-to-dry transition. In the static contact test, the normal load decreased from $1 \mathrm{mN}$ to a minimum value of $392 \mu \mathrm{N}$ and then recovered as the water evaporated. The static contact experiment confirmed that during the wet-to-dry transition, the normal load decreased with increasing indentation depth and capillary adhesion. The friction peak in the sliding experiment was attributed to the combined effect of the increased adhesive capillary force from nano/micro/macroscale liquid bridges and increased plowing during the wet-to-dry transition.

\section{Acknowledgements}

The authors gratefully acknowledge the financial support from the National Natural Science Foundation of China (Nos. 51875152, 51875153, and 51975174). 
Open Access This article is licensed under a Creative Commons Attribution 4.0 International License, which permits use, sharing, adaptation, distribution and reproduction in any medium or format, as long as you give appropriate credit to the original author(s) and the source, provide a link to the Creative Commons licence, and indicate if changes were made.

The images or other third party material in this article are included in the article's Creative Commons licence, unless indicated otherwise in a credit line to the material. If material is not included in the article's Creative Commons licence and your intended use is not permitted by statutory regulation or exceeds the permitted use, you will need to obtain permission directly from the copyright holder.

To view a copy of this licence, visit http://creativecommons.org/licenses/by/4.0/.

\section{References}

[1] de Gennes P G, Brochard-Wyart F, Quéré D. Capillarity and Wetting Phenomena: Drops, Bubbles, Pearls, Waves. New York: Springer, 2004.

[2] Deleau F, Mazuyer D, Koenen A. Sliding friction at elastomer/ glass contact: Influence of the wetting conditions and instability analysis. Tribol Int 42(1): 149-159 (2009)

[3] Persson B N J. Capillary adhesion between elastic solids with randomly rough surfaces. $J$ Phys: Condens Matter 20(31): 315007 (2008)

[4] Roberts A D, Tabor D. The extrusion of liquids between highly elastic solids. Proc Roy Soc A: Math Phys Eng Sci 325(1562): 323-345 (1971)

[5] Le Rouzic J, Le Bot A, Perret-Liaudet J, Guibert M, Rusanov A, Douminge L, Bretagnol F, Mazuyer D. Friction-induced vibration by Stribeck's law: Application to wiper blade squeal noise. Tribol Lett 49(3): 563-572 (2013)

[6] Bocquet L, Charlaix E, Ciliberto S, Crassous J. Moistureinduced ageing in granular media and the kinetics of capillary condensation. Nature 396(6713): 735-737 (1998)

[7] Drechsler P, Federle W. Biomechanics of smooth adhesive pads in insects: Influence of tarsal secretion on attachment performance. J Comp Physiol A 192(11): 1213-1222 (2006)

[8] Johnson K L, Kendall K, Roberts A D. Surface energy and the contact of elastic solids. Proc Roy Soc A: Math Phys Eng Sci 324(1558): 301-313 (1971)

[9] Kendall K. The adhesion and surface energy of elastic solids. J Phys D: Appl Phys 4(8): 1186-1195 (1971)
[10] Tabor D. Surface forces and surface interactions. J Colloid Interface Sci 58(1): 2-13 (1977)

[11] Derjaguin B, Muller V, Toporov Y. On different approaches to the contact mechanics. $J$ Colloid Interface Sci 73(1): 293-294 (1980)

[12] Maugis D. Adhesion of spheres: The JKR-DMT transition using a dugdale model. J Colloid Interface Sci 150(1): 243-269 (1992)

[13] Reedy Jr E D. Thin-coating contact mechanics with adhesion. J Mater Res 21(10): 2660-2668 (2006)

[14] Hill I J, Sawyer W G. Energy, adhesion, and the elastic foundation. Tribol Lett 37(2): 453-461 (2010)

[15] Dickrell III D J, Sawyer W G. Intermolecular forces, adhesion, and the elastic foundation. Tribol Lett 50(2): 245-260 (2013)

[16] Loskofsky C, Song F, Newby B M Z. Underwater adhesion measurements using the JKR technique. $J$ Adh 82(7): 713-730 (2006)

[17] Martin P, Silberzan P, Brochard-Wyart F. Sessile droplets at a solid/elastomer interface. Langmuir 13(18): 4910-4914 (1997)

[18] Wang Z X. Polydimethylsiloxane mechanical properties measured by macroscopic compression and nanoindentation techniques. Master's Thesis. Florida (USA): University of South Florida, 2011.

[19] Maegawa S, Itoigawa F, Nakamura T. Dynamics in sliding friction of soft adhesive elastomer: Schallamach waves as a stress-relaxation mechanism. Tribol Int 96: 23-30 (2016)

[20] Bennett A I, Harris K L, Schulze K D, Urueña J M, McGhee A J, Pitenis A A, Müser M H, Angelini T E, Sawyer W G. Contact measurements of randomly rough surfaces. Tribol Lett 65(4): 134 (2017)

[21] Krick B A, Vail J R, Persson B N J, Sawyer W G. Optical in situ micro tribometer for analysis of real contact area for contact mechanics, adhesion, and sliding experiments. Tribol Lett 45(1): 185-194 (2012)

[22] Rowe K G, Bennett A I, Krick B A, Gregory Sawyer W. In situ thermal measurements of sliding contacts. Tribol Int 62: 208-214 (2013)

[23] Foord C A, Wedeven L D, Westlake F J, Cameron A. Optical elastohydrodynamics. Proc Inst Mech Engineers 184(1): 487-505 (1969)

[24] McFarlane J S, Tabor D. Adhesion of solids and the effect of surface films. Proc Roy Soc A: Math Phys Sci 202(1069): 224-243 (1950)

[25] Megias-Alguacil D, Gauckler L J. Analysis of the capillary forces between two small solid spheres binded by a convex liquid bridge. Powder Technol 198(2): 211-218 (2010) 
[26] Carambassis A, Jonker L C, Attard P, Rutland M W. Forces measured between hydrophobic surfaces due to a submicroscopic bridging bubble. Phys Rev Lett 80(24): 5357-5360 (1998)

[27] Fukahori Y, Gabriel P, Busfield J J C. How does rubber truly slide between Schallamach waves and stick-slip motion?

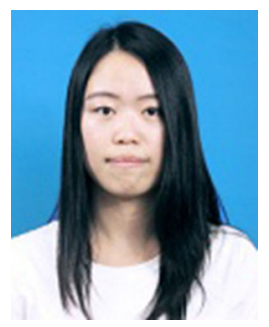

Tianyan GAO. She received her bachelor degree in aerocraft manufacture engineering in 2017 from Hefei University of Technology,

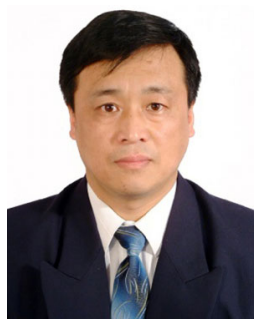

Kun LIU. He received his M.S. degree in 1988 from Hefei University of Technology, Hefei, China, and received his Ph.D. degree in the Institute of Lubrication Theory and
Wear 269(11-12): 854-866 (2010)

[28] Pawlak Z, Urbaniak W, Oloyede A. The relationship between friction and wettability in aqueous environment. Wear 271(9-10): 1745-1749 (2011)

[29] Maegawa S, Nakano K. Mechanism of stick-slip associated with Schallamach waves. Wear 268(7-8): 924-930 (2010)

Hefei, China. Now, she is a Ph.D. student in the Institute of Tribology at the same university. Her research interests include rubber friction and interfacial wetting.

Bearings in 1995 from Xi'an Jiaotong University, Xi'an, China. His current position is a professor and the director of the Institute of Tribology. His research area mainly focuses on the tribology design. 